\section{Slaves of Fashion}

I really have to thank Jef Raskin for his article "User Interface Designers, Slaves of Fashion" (Queue 1(6), September 2003). For some reason, this topic seems to be completely ignored within almost all modern computing environments. Therefore, trying to understand the current slew of computer interfaces can be painful to a veteran in the field like me.

In my experience, no one complains about the interfaces we use. As a result, there is only one interface class in the computer science school at the University of Waterloo, and I have yet to find any good books on interface design. So my question boils down to this: What should I read in order to orient myself in the interface design world?

Andrew Eberbach

JEF RASKIN RESPONDS: I thank Mr. Eberbach for his kind words about my article. There are too many useful books available to give a comprehensive list, so I'll only mention a few.

For getting started there is Don Norman's enjoyable The Design of Everyday Things (Basic Books, 2000) for motivation and a feel for the problems that users have. Steve Krug's Don't Make Me Think (New Riders, 2000) is a short, Web-oriented book of hints (the title is the best hint of all). There is also Deborah Mayhew's Principles and Guidelines in Software User Interface Design (Pearson Education, 1997), which, along with books by Shniederman, Nielsen, and others, offers many heuristics. Deeper understanding can be had from Card, Moran, and Newell's classic The Psychology of Human-Computer Interaction (Lawrence Erlbaum, 1983), and perhaps I can be forgiven for mentioning my own book, The Humane Interface (Addison-Wesley, 2000), in this regard.

I read Jef Raskin's interesting article "User Interface Designers, Slaves of Fashion" (Queue 1(6), September 2003).

I agree that executing two cuts in a row without an intervening paste should perhaps negate the first cut. However, some software that I use doesn't have a delete capability, so I use cut to delete. In that case, negating a first cut isn't helpful.

Selecting move instead of cut and paste sounds promising, but sometimes it's difficult to figure out the cursor's exact location without clicking, which would probably cancel out my original text selection.

A suggestion: How about a visible clipboard (as on the Macs of old)? The cut could be indicated by an icon that one would have to select, and it would otherwise disappear after pasting.

$$
\text { Mike Frisch }
$$

JEF RASKIN RESPONDS: I am grateful to Mr. Frisch for his comment. His model for replacing cut and paste commands with move and copy commands has exactly the problems he cites. When implemented appropriately, however, so that one can choose an insertion point without losing the selection to be moved, there is no problem. To see how this works in practice, there is a detailed specification and demo software under the title "THE" (The Humane Environment) at http://www.jefraskin.com.

Any software that "doesn't have a delete capability" is even worse than that which relies on cut and paste to move information. You have my condolences for having had to use such software.

\section{On Heretics and Zealots}

I just finished reading the summer issue (Queue 1(5), July/ August 2003). Great job! It was the first time in about 25 years (since I was a graduate student reading Computing Surveys) that I've read an ACM general publication from cover to cover.

As an avid TiVo owner and Linux fan, I was particularly excited to read Jim Barton's article "From Server Room to Living Room." The sidebars and resources in Paul Ferris's article "The Age of Open Source Corporate Enlightenment" also were quite interesting. On the other hand, I did find Greg Lehey's article, "Closed Source Fights Back," too partisan.

$$
\text { Mark Scott }
$$

\section{The FTC and Spam}

Just a quick note to say that I really enjoyed Eric Allman's "Spam, Spam, Spam, Spam, the FTC, and Spam" (Queue 1(6), September 2003).

I'd love to see an update in a year!

$$
\text { Harry Rudin }
$$

\section{PLEASE SEND US YOUR FEEDBACK}

You can reach us at feedback@acmqueue.com.

We edit letters for content, style, and length. $Q$ 